\title{
Análise acústica e sociolinguística das vogais médias pretônicas faladas em Montanha - ES
}

\author{
Acoustic and sociolinguistic analysis of pre-stressed mid vowels spoken in Montanha - ES \\ Alexsandro Rodrigues Meireles \\ Viviany de Paula Gambarini \\ Maria Marta Pereira Scherre \\ Universidade Federal do Espírito Santo - Vitória - Espírito Santo - Brasil
}

$\diamond$

\begin{abstract}
Resumo: Este artigo apresenta uma análise acústica e sociolinguística das vogais médias pretônicas de Montanha, cidade do extremo-norte do Espírito Santo. Para isso, selecionamos 4 informantes, dois homens e duas mulheres, de duas faixas etárias (18-30 e 31-50 anos). O corpus foi obtido pela apresentação de figuras inseridas na frase-veículo "Digo baixinho", repetidas cinco vezes por falante. Através do plug-in Akustyk, no programa Praat, extraímos os valores do primeiro e segundo formantes das vogais estudadas. Como resultado, observamos que as vogais médias-baixas de Montanha são mais baixas se comparadas às do Rio de Janeiro, Salvador e Vitória. Em relação à anterioridade/posterioridade, Montanha apresentou vogais anteriores bem mais anteriorizadas e posteriores bem mais posteriorizadas do que a das outras cidades. Quanto à análise sociolinguística, a variável faixa etária foi selecionada, pelo programa GoldVarb X, como a mais significativa na manutenção da vogal média-alta em posição pretônica, sendo a faixa de 18 a 30 anos a maior responsável pela manutenção.
\end{abstract}

Palavras-chave: Vogais médias pretônicas; Variação linguística; Análise acústica; Dialeto capixaba

\begin{abstract}
This article presents acoustic and sociolinguistic descriptions of pre-stressed mid vowels in Montanha, a city at the extreme north of Espírito Santo state. We selected four informants, two men and two women, in two age groups (18-30 and 31-50 years). The corpus was obtained from the presentation of figures inserted into the carrier sentence "Digo baixinho" and repeated five times by speaker. Using the plug-in Akustyk within Praat, we extracted the values of the first and second formants of the vowels. As a result, we noticed that the medium-high vowels of Montanha are lower compared to those of Rio de Janeiro, Salvador and Vitória. About anteriority/posteriority, Montanha presented anterior vowels much more anteriorized, and posterior vowels much more posteriorized, compared to the other cities. Regarding sociolinguistic analysis, the age variable was selected by GoldVarb X program as the most significant for maintaining the medium-high vowel in pre-stressed position, and the range of 18 to 30 was the most responsible for this maintenance.
\end{abstract}

Keywords: Pre-stressed mid vowels; Linguistic variation; Acoustic analysis; Capixaba dialect

\section{Introdução}

Nas últimas décadas, um grande número de pesquisas que analisam a variação das vogais médias em posição pretônica tem surgido e se mostrado importante na descrição da diversidade linguística e das áreas dialetais do país. Um dos incentivos para a realização desses trabalhos é a descrição feita pelo dialetólogo Antenor Nascentes (1953), que, a partir de impressões perceptivas da produção de vogais médias pretônicas, propôs a divisão do Brasil em duas grandes áreas dialetais: o Norte e o Sul. Segundo o pesquisador,

de um modo geral se pode reconhecer uma grande divisão: norte e sul; norte, até a Baía e sul, daí para baixo. No sul não há vogais pretônicas abertas antes do acento (salvo determinados casos de derivação) e a cadência é diferente da do norte. (NASCENTES, 1953, p. 19-20) 
Nascentes (1953) divide essas áreas, ainda, em seis subfalares: o amazônico, o nordestino, o baiano, o mineiro, o fluminense e o sulista, além de estabelecer um território indefinido. Nessa divisão, conforme observado na Figura 1, o estado do Espírito Santo, juntamente com o Rio de Janeiro e parte de Minas Gerais, foi introduzido no subfalar fluminense.

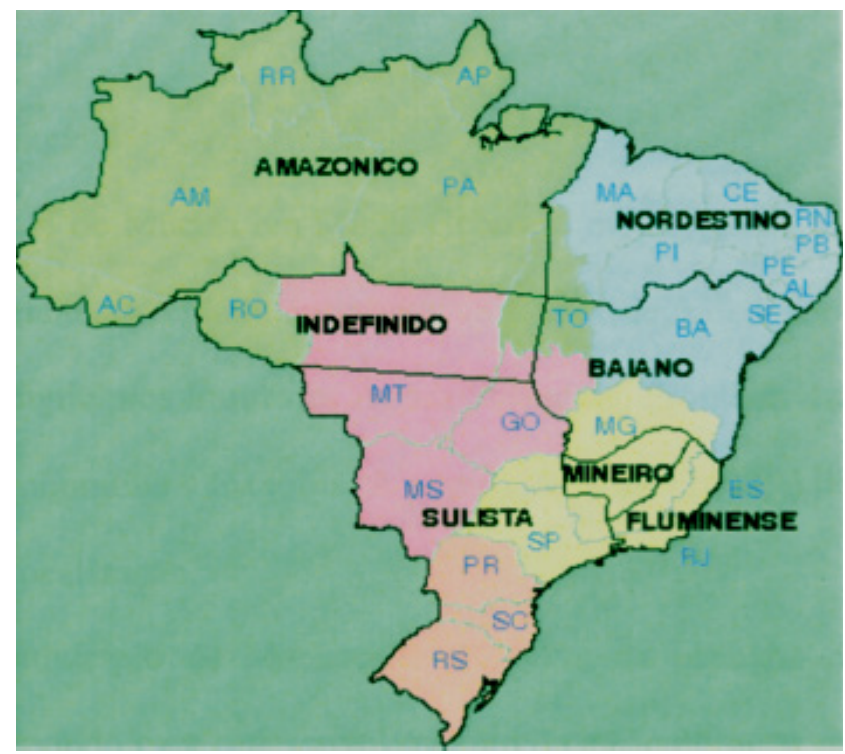

Figura 1. Divisão dialetal do Brasil proposta por Antenor Nascentes. Fonte: Nascentes (1953, p. 19).

Desde o trabalho de Nascentes (1953), muitos pesquisadores têm se empenhado em analisar a realização das vogais médias pretônicas a fim de auxiliar na descrição linguística das diversas regiões do país. Destacamos o trabalho pioneiro de Bisol (1981), que, a partir dos pressupostos da Teoria da variação e mudança linguística, observou, na fala de 44 indivíduos do Rio Grande do Sul, a variação da pretônica a partir do fenômeno da harmonização vocálica, que consiste em a vogal média pretônica assimilar a altura da vogal da sílaba seguinte. Especificamente, em seu trabalho, Bisol (1981) verificou que a vogal anterior [i], quando presente na sílaba seguinte à pretônica, favorecia a elevação ${ }^{1}$ de $[\mathrm{e}]$ para [i] e de [o] para $[\mathrm{u}]$, produzindo, por exemplo, qu[i]rido e $b[u]$ nito, e que a vogal alta posterior $[\mathrm{u}]$ favorecia na elevação de [o] para $[\mathrm{u}]$, produzindo casos como acustuma.

Em relação ao estudo das vogais médias pretônicas no falar capixaba, temos o trabalho prosódico de Abaurre-Gnerre (1981), que apresenta de que forma essas vogais são realizadas nessa variedade do português brasileiro (doravante PB). A linguista observou, além de

Neste artigo, utilizamos as palavras elevação, alçamento e alteamento como termos intercambiáveis. casos de elevação, a presença de casos de abaixamento, como em $p[\varepsilon]$ teca, em que não há a manutenção da pronúncia [e] da vogal como média-alta, mas sim a produção de uma vogal média-baixa $[\varepsilon]$. Esta constatação vai de encontro ao estabelecido por Nascentes (1953), pois este autor inclui o Espírito Santo em um dos subfalares do sul do Brasil, o fluminense, em que, para ele, não haveria o abaixamento de vogais médias.

Outros trabalhos estudaram as ocorrências das vogais médias pretônicas no Espírito Santo. Celia (2004), por exemplo, ao analisar a fala de nove informantes do sexo feminino da cidade de Nova Venécia, localizada a $255 \mathrm{~km}$ de Vitória, capital do estado, observou o alçamento, o abaixamento e a manutenção das vogais médias-altas nessa região. A autora estratificou os falantes em três faixas etárias $(25$ a $35 ; 36$ a $55 ; 56$ ou mais) e observou que, em relação ao alçamento, há um pequeno favorecimento pela faixa de 56 ou mais anos de idade. Celia (2004) levanta a hipótese, já pensada por Bisol (1981), de que esse fenômeno estaria em vias de regressão, tendo em vista que os jovens alçariam menos as vogais médias pretônicas. A autora, entretanto, aponta esse fato com cautela, pois acredita que seja necessário um maior número de dados para que se possa confirmar esse processo de mudança. Em relação ao abaixamento, Celia (2004) observa um percentual de $18,9 \%$ no falar de Nova Venécia, semelhante ao que Leite (2014) encontrou dez anos depois para Vitória: 18,3\%.

É importante destacar que, ainda que haja casos de alteamento e de abaixamento em Nova Venécia, a maior ocorrência de vogais médias pretônicas encontradas por Celia (2004) é de manutenção da vogal média-alta, ou seja, os falantes utilizaram mais as variantes [e] e [o] nessa posição. Em suas conclusões, a linguista afirma que "os estudos sobre a variação das vogais médias pretônicas revelam que embora o alteamento dessas vogais seja bastante comum, em praticamente todos os dialetos (talvez com exceção dos falares do Nordeste e Norte) as variantes mais empregadas são as médias [e] e [o]" (CELIA, 2004, p. 99).

Sobre as vogais médias pretônicas em Vitória, capital do Espírito Santo, Leite (2014) observou também o alçamento, o abaixamento e a manutenção. A autora aponta a importância da harmonização vocálica no abaixamento das vogais, pois, segundo ela, "os ambientes em que as médias-abertas $[\varepsilon, \supset]$ e a baixa [a] central se encontravam em posição tônica foram os que mais favoreceram o abaixamento" (LEITE, 2014, p. 95). Celia (2004) e Leite (2014) encontraram uma frequência de abaixamento bem maior em Vitória (18,3\%) e Nova Venécia $(18,9 \%)$ do que foi encontrado para o falar carioca $(3,3 \%)$ por Yacovenco (1993). A frequência de abaixamento em território capixaba é, entretanto, menor que a encontrada por Silva 
$(1989 ; 1991)$ para Salvador $(59,3 \%)$. Tais dados, segundo Celia (2004) e Leite (2014), podem indicar que o Espírito Santo esteja em uma região de transição entre os falares do Sul e do Norte.

Nesse sentido, nosso artigo compara nossos resultados para a cidade de Montanha, localizada ao norte do Espírito Santo e fronteiriça ao território baiano, com os resultados das autoras citadas. Além disso, apresentamos resultados acústicos, a partir do levantamento do primeiro e segundo formantes de cada dado do nosso corpus, a fim de auxiliar a descrição fonético-acústica do dialeto capixaba. Esses resultados serão também confrontados aos encontrados por Moraes et al. (2002), para a cidade de Salvador e Rio de Janeiro, e aos resultados para Vitória encontrados por Leite (2014).

\section{Pressupostos teóricos}

Considerando que o fenômeno estudado é altamente variável, encontramos na Sociolinguística Variacionista o aporte teórico capaz de nos auxiliar na análise dos dados. Além disso, nossa pesquisa também baseou-se em pressupostos da fonética acústica, pois esta tem se mostrado muito importante nos estudos da linguagem, na medida em que permite visualizar e caracterizar o detalhe fonético a partir do estudo das propriedades físicas dos sons da fala, como intensidade, duração, frequência fundamental e conteúdo espectral da onda sonora.

\subsection{Sociolinguística Variacionista}

Os estudos sociolinguísticos, assim como os que os antecederam, entendem a língua como um sistema, entretanto, tal sistema, para a Sociolinguística, não é homogêneo, já que não é formado apenas por regras categóricas, mas por regras variáveis, de forma ordenada, nos termos de Labov (2008 [1972]). Além disso, ponderam que aspectos linguísticos ou internos e sociais ou externos são fundamentais para o entendimento da variação e da mudança linguística.

Na variação entre [e] e [i], por exemplo, o alteamento da vogal pode estar relacionado com características do segmento vocálico seguinte, como na palavra medida, em que a vogal [i] da sílaba seguinte à da vogal pretônica pode levar à harmonização vocálica, resultando em midida. Como fatores externos, temos, por exemplo, a variação diatópica, ou regional, e a diastrática, ou social. Características do falante, como a faixa etária ou o sexo/gênero, podem também ser fundamentais para o entendimentos dos processos variáveis.

É importante salientar que o estudo com diferentes faixas etárias mostra-se importante na análise da mudança em tempo aparente, ou seja, em função do "comportamento diferenciado dos falantes em várias faixas etárias" (LABOV, 2008 [1972], p. 318). Busca-se observar, por exemplo, em que faixa etária ocorrem mais processos de alçamento, abaixamento ou manutenção de vogais médias pretônicas, com o objetivo de inferir eventuais processos de mudança por meio da análise dos dados sincrônicos. No trabalho de Bisol (1981), acerca dos ambientes favorecedores ou não do alçamento dessas vogais no falar gaúcho, a autora observou que os mais velhos utilizavam mais a regra do alçamento e que os jovens utilizavam mais a manutenção das vogais médiasaltas. Este fato pode indicar que a regra de alçamento esteja em vias de regressão nessa variedade do $\mathrm{PB}$, o que também foi observado por Yacovenco (1993), para a fala do Rio de Janeiro.

\subsection{Fonética Acústica e Teoria fonte-filtro da produção de fala}

A fonética acústica estuda o sinal acústico, ou seja, "o evento físico que é transmitido nas telecomunicações ou é gravado em fitas magnéticas, CDs e outras mídias" (KENT \& READ, 2015, p. 24). É nesse sinal que encontramos a mensagem linguística da fala e sobre o qual recairá nossa análise. Considerando que uma vogal /i/, por exemplo, possui um padrão de frequência diverso de uma vogal $/ \mathrm{u} /$, uma análise acústica torna-se importante na diferenciação das variedades linguísticas, pois pode oferecer padrões específicos de dados acústicos para diferentes regiões. Entre as teorias que visam analisar as relações acústicoarticulatórias da fala, a teoria fonte-filtro da produção de fala de Gunnar Fant (1960) é a mais utilizada. Neste trabalho, aplicaremos essa teoria à análise de vogais.

Segundo Fant (1970 [1960], p. 15), a onda sonora consiste no resultado de um sistema de transmissão selecionador de frequências que funciona como um filtro atuando ao longo do trato vocal, em resposta a uma ou mais fontes sonoras. Na produção das vogais, o vozeamento é a fonte de energia. Além disso, na produção dos segmentos vocálicos, a passagem da corrente de ar não é interrompida, ou seja, não há obstrução ou fricção no trato vocal. Este acaba por funcionar como um sistema de transmissão selecionador de frequências, ou um filtro, que gera diferentes frequências de ressonâncias, denominadas formantes.

Segundo Ladefoged (2001, p. 39), é possível analisar os sons vocálicos a partir da frequência de seus formantes. O linguista aponta, ainda, que uma boa representação das vogais de uma determinada língua corresponde a um gráfico com as médias dos valores do primeiro e segundo formantes de cada vogal de um grupo de falantes, conhecido como gráfico de F1×F2 (LADEFOGED, 2001, p. 39). Dessa forma, foram analisadas, neste estudo, 
as frequências do primeiro formante (F1) e do segundo formante (F2), tendo em vista que estes são tidos como os principais para determinar a qualidade fonética dos segmentos vocálicos. Os valores de F1 relacionam-se à altura da língua durante a produção dos sons da fala, e os de F2 ligam-se à anterioridade/posteridade da língua.

A frequência do primeiro formante varia inversamente com a altura da língua na produção da vogal, ou seja, quanto mais alta a vogal, menor sua frequência para F1. Dessa forma, a vogal baixa [a] terá o valor de F1 maior que o de uma vogal alta [i], por exemplo. Quanto aos valores de $\mathrm{F} 2$, relacionados à anterioridade/posteridade da articulação das vogais, os segmentos vocálicos posteriores, como $[\mathrm{u}]$, assumem frequências relativamente baixas para esse formante, enquanto as vogais anteriores, como [i], possuem frequências relativamente altas (LADEFOGED \& JOHNSON, 2011, p. 196).

No estudo das vogais médias pretônicas de Montanha, a análise de F1 e F2 é importante, na medida em que nos permite dialogar com o estudo de Nascentes (1953), que inclui o Espírito Santo nos subfalares do sul do país. É necessário, para isso, comparar os resultados dessa região aos encontrados para outras localidades. Neste artigo, comparamos nossos resultados com os encontrados por Moraes et al. (2002) para Salvador e Rio de Janeiro, além dos resultados encontrados por Leite (2014), para o falar de Vitória, a fim de, neste caso, comparar duas localidades do mesmo estado.

\section{Metodologia}

\subsection{Comunidade estudada e seleção dos informantes}

Montanha é uma cidade que se localiza ao Norte do Espírito Santo, a $334 \mathrm{~km}$ da capital do estado, Vitória, e faz divisa com Bahia e Minas Gerais (Fig. 2). Essa cidade, no subfalar fluminense, entretanto, por estar em uma zona fronteiriça, esperamos encontrar na fala de nossos informantes características do subfalar baiano.

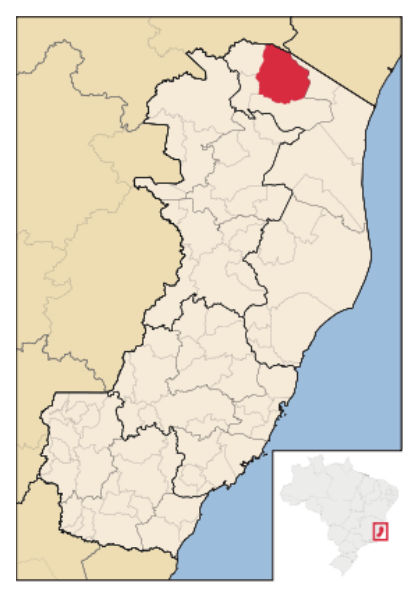

Figura 2. Mapa do Espírito Santo, com a cidade de Montanha destacada.

Fonte: <https://commons.wikimedia. org/wiki/File:EspiritoSanto_Municip_ Montanha.svg?uselang $=\mathrm{pt}>$, acesso em: 01 jan. 2016.
Para nosso artigo, trabalhamos com o corpus obtido da fala de quatro pessoas, estratificadas de acordo com a faixa etária e sexo/gênero. Todos os falantes têm o ensino médio completo (Tab. 1).

Tabela 1. Informantes

\begin{tabular}{lcrrrr}
\hline \multicolumn{5}{c}{ Informantes de Montanha - ES } \\
\hline Faixa etária & \multicolumn{1}{c}{$18-30$ anos } & \multicolumn{3}{c}{$31-50$ anos } & Total \\
Sexo/Gênero & $M$ & F & M & F & \\
& 1 & 1 & 1 & 1 & 4 \\
\hline
\end{tabular}

\subsection{0 corpus}

O corpus foi obtido a partir da gravação da fala dos informantes com um gravador H1 Handy Recorder, da marca Zoom. Para isso, foram apresentados a cada informante 76 estímulos visuais inseridos na frase veículo "Digo baixinho". Além disso, a gravação dos estímulos foi repetida cinco vezes por falante, resultando, dessa forma, em 1520 dados para análise. Para este artigo, entretanto, analisamos a primeira e a quarta repetição, a fim de estabelecermos um contraste entre elas. Isso reduziu nossos dados para 608. Escolhemos essas repetições específicas, para discutir se, ao iniciar a gravação, o informante monitoraria mais a própria fala, já que estava diante de um método mais controlado de gravação.

Foram escolhidos vocábulos que poderiam permitir o alçamento $([\mathrm{e}] \rightarrow[\mathrm{i}],[\mathrm{o}] \rightarrow[\mathrm{u}]$ ), a manutenção ([e] e $[\mathrm{o}]$ ) ou o abaixamento $([\mathrm{e}] \rightarrow[\varepsilon],[\mathrm{o}] \rightarrow[\mathrm{\rho}])$ das vogais estudadas: /e/ e /o/. Para isso, selecionamos palavras cujas tônicas tivessem uma das sete vogais orais do (PB): altas [i] e [u]; médias-altas [e] e [o]; baixa [a]; e médias-baixas $[\varepsilon]$ e $[\supset] .^{2}$ Além disso, a vogal tônica vem acompanhada de consoantes de três pontos de articulação diferentes: labial, alveolar e velar, a fim de que possamos observar a influência delas sobre os formantes das vogais. Finalmente, analisaremos três estruturas de palavras: 1 - palavras com duas sílabas, sendo a primeira pretônica e a segunda tônica. Ex.: bobó, bebê; 2 - palavras com três sílabas, sendo a primeira pretônica, a segunda tônica e a terceira átona. Ex.: cozinha, pepino; 3 - palavras com três sílabas, sendo as duas primeiras pretônicas e a última tônica. Nessa estrutura, ambas as sílabas pretônicas possuem a mesma vogal. Ex.: cotovelo, pessegueiro.

No recorte deste estudo, analisamos apenas as vogais pretônicas seguidas de tônicas, ou seja, as mais próximas das vogais tônicas. Como nosso estudo também consiste

\footnotetext{
2 Em alguns casos, quando não encontramos palavras com determinada vogal oral na sílaba tônica, foram utilizados ditongos (ex.: prefeito, sereia) ou vogais nasalisadas (Ex.: cegonha).
} 
em uma análise acústica, escolhemos apenas esse contexto silábico. Apesar disso, é importante destacar que uma vogal pretônica pode assimilar o traço de uma pretônica seguinte e não apenas o traço de uma tônica, conforme verificado, por exemplo, por Yacovenco (1993), Celia (2004) e Leite (2014). Além disso, outros fatores podem influenciar a variação das vogais médias pretônicas, como as consoantes adjacentes ou ainda características do próprio item lexical, conforme verificado por Viegas (1995).

\subsection{Análise Acústica - Akustyk, Praat}

A partir do plug-in Akustyk, no Praat, foram obtidas as medidas de frequências do primeiro e segundo formantes, em $\mathrm{Hz}$, das vogais estudadas que auxiliarão a análise acústica. ${ }^{3}$ Seguindo os passos de Miranda (2012), tais medidas foram obtidas no entorno do ponto central da duração da vogal, a fim de que os sons vizinhos consonantais não exercessem tanta influência sobre elas. Além disso, também fizemos o controle da largura de banda de cada formante, por meio da escolha do valor mais apropriado, que consiste em um menor valor de largura de banda do formante.

Após o levantamento do $\mathrm{F} 1$ e F2 de todas as pretônicas do corpus, calculamos, no Excel, a média dos valores de formantes de Vitória e de Montanha. É importante destacar que o plug-in Akustyk fornece esses dados de maneira normalizada, a fim de minimizar as diferenças fisiológicas dos falantes (como o tamanho do trato vocal de cada um deles). Tal normalização é necessária, pois, se trabalhássemos com dados brutos, os valores dos formantes se distanciariam muito entre os falantes da mesma região, tendo em vista que suas características fisiológicas influenciariam as frequências dos formantes

\subsection{Análise estatística - GoldVarb X}

Para a análise estatística de cunho variacionista, foi utilizado o programa GoldVarb X (SANKOFF, TAGLIAMONTE \& SMITH, 2005). Em nossa análise, consideramos as variáveis externas faixa etária, sexo/ gênero do falante e a primeira e a quarta repetições da palavra.

Além disso, controlamos as seguintes variáveis internas: a natureza da vogal tônica; a anterioridade/ posterioridade da vogal pretônica; o ponto de articulação da consoante precedente; o ponto de articulação da consoante seguinte; e a estrutura da palavra.

\section{Resultados}

\subsection{Resultados acústicos}

Para obtermos os resultados das medidas acústicas da fala de Montanha, extraímos, do plug-in Akustyk no Praat, os valores de F1 e F2 de duas palavras por vogal analisada para cada informante e, em seguida, calculamos a média de cada um desses valores. Para definirmos quais eram as vogais, nos baseamos nos valores de formantes encontrados por Miranda (2012, p. 78) para as sete vogais orais do PB. Como o alçamento da vogal [e] para [i] quase não ocorreu na fala de Montanha, retiramos os casos de [i] da análise acústica e estatística. Na Tabela 2 e no Gráfico 1, portanto, apresentamos, de maneira comparativa, as medidas encontradas para Montanha e para Vitória (LEITE, 2014, p. 127), além dos valores para o Rio de Janeiro e Salvador (MORAES et al., 2002, p. 40) para cinco vogais.

Em relação ao eixo vertical, relacionado à altura das vogais, observamos, no Gráfico 1, que as variantes médias-baixas $[\varepsilon]$ e $[\supset]$, na fala de Montanha, apre-

Tabela 2. Médias de F1 e F2 para Rio de Janeiro, Vitória, Montanha e Salvador

\begin{tabular}{|c|c|c|c|c|c|c|c|c|}
\hline \multicolumn{9}{|c|}{ Medidas acústicas das vogais médias pretônicas de Rio de Janeiro, Vitória, Montanha e Salvador } \\
\hline \multirow{2}{*}{ Vogais } & \multicolumn{2}{|c|}{ Rio de Janeiro } & \multicolumn{2}{|c|}{ Vitória } & \multicolumn{2}{|c|}{ Montanha } & \multicolumn{2}{|c|}{ Salvador } \\
\hline & Média de F1 & Média de F2 & Média de F1 & Média de F2 & Média de F1 & Média de F2 & Média de F1 & Média de F2 \\
\hline [e] & 433 & 1884 & 527 & 1878 & 463 & 2093 & 413 & 1897 \\
\hline$[\varepsilon]$ & 485 & 1855 & 618 & 1820 & 639 & 1945 & 488 & 1622 \\
\hline [0] & 541 & 991 & 630 & 1232 & 640 & 1087 & 511 & 1023 \\
\hline [o] & 418 & 971 & 570 & 1205 & 471 & 1002 & 408 & 1035 \\
\hline$[\mathrm{u}]$ & 352 & 948 & 455 & 1088 & 448 & 906 & 325 & 1025 \\
\hline
\end{tabular}

\footnotetext{
3 Fonte: $<$ http://bartus.org/akustyk/>. Infelizmente, o site foi descontinuado e, atualmente, o plug-in Akustyk não se encontra mais disponível para download.
} 
sentaram um valor maior de F1, se comparado com as mesmas variantes das outras cidades. Isso significa que essas vogais são mais baixas nessa região. É interessante observar, ainda, que os valores de F1 das vogais médiasbaixas estão mais próximos aos valores encontrados para Vitória, o que pode vir a indicar um padrão para a variedade linguística do Espírito Santo.

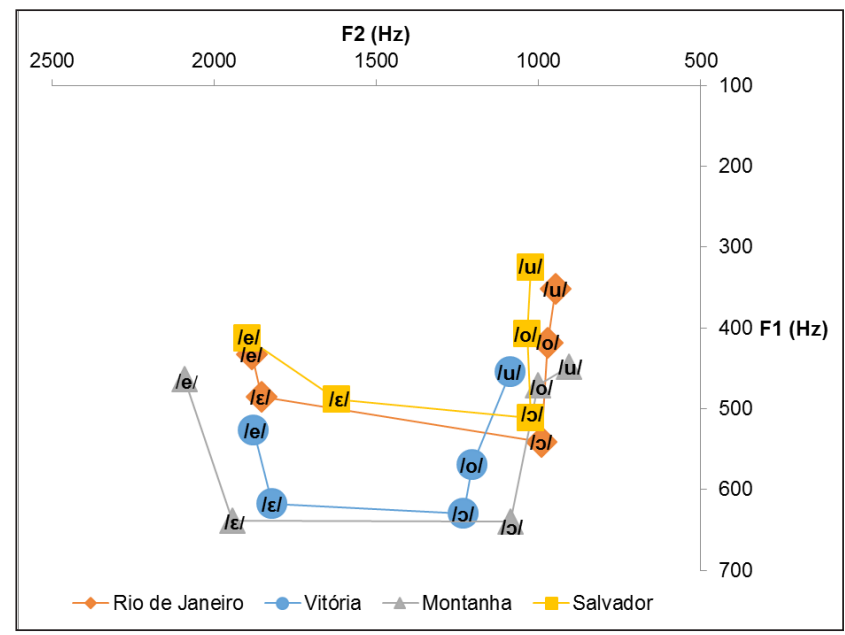

Gráfico 1. Medidas de F1-F2 para Rio Janeiro, Vitória, Montanha e Salvador

Ainda sobre a altura das vogais, percebe-se que os valores de $\mathrm{F} 1$ das vogais pretônicas [o] e [u] de Montanha estão muito mais próximos entre si do que os das outras cidades, principalmente de Vitória, em que /o/ é muito mais baixo do que para as demais regiões.

Em relação ao eixo horizontal, relacionado à anterioridade/posterioridade da língua no momento de fala, observamos, no Gráfico 1 , que as vogais [e] e $[\varepsilon]$ se mostraram bem mais anteriores na fala de Montanha do que as vogais das outras regiões, inclusive de Vitória. Em comparação a Vitória, Montanha apresentou, ainda, vogais [o], [o] e [u] mais posteriorizadas, dado o menor valor de F2 para elas. A maior anteriorização das vogais $[\mathrm{e}]$ e $[\varepsilon]$ de Montanha e a maior posteriorização das vogais [o], [o] e [u] indicam que, em relação às vogais de Vitória, Montanha possui um espaço acústico mais periférico.

\subsection{Resultados variacionistas}

A Tabela 3 apresenta os resultados da distribuição do uso das vogais médias pretônicas na fala de Montanha, encontrados no GoldVarb X, e os compara com os resultados de Yacovenco (1993, p. 63), para o Rio de Janeiro; de Leite $(2014$, p. 55) para a fala de Vitória; de Celia (2004, p. 61), para Nova Venécia; e de Silva (1989, p. $106 ; 1991$, p. 82), para a fala de Salvador.
Tabela 3. Distribuição das vogais médias pretônicas em cinco cidades brasileiras

\begin{tabular}{lccc}
\hline $\begin{array}{c}\text { Variedades } \\
\text { linguísticas }\end{array}$ & $\begin{array}{c}\text { Médias-altas } \\
\text { [e] e [o] }\end{array}$ & $\begin{array}{c}\text { Altas } \\
{[\mathrm{i}] \text { e [u] }}\end{array}$ & $\begin{array}{c}\text { Médias-baixas } \\
{[\varepsilon] \text { e [0] }}\end{array}$ \\
\hline Rio de Janeiro-RJ & $2674 / 4189=63,8 \%$ & $1378 / 4189=32,9 \%$ & $137 / 4189=3,3 \%$ \\
Vitória-ES & $1271 / 1954=65,4 \%$ & $327 / 1954=16,3 \%$ & $356 / 1954=18,3 \%$ \\
Nova Venécia-ES & $\mathbf{6 4 , 2} \%$ & $16,9 \%$ & $18,9 \%$ \\
Montanha-ES & $486 / 608=79,9 \%$ & $17 / 608=2,8 \%$ & $105 / 608=17,3 \%$ \\
Salvador-BA & $610 / 3269=18,7 \%$ & $718 / 3269=22 \%$ & $1941 / 3269=59,3 \%$ \\
\hline
\end{tabular}

Verificamos que, assim como as cidades da região Sudeste listadas na Tabela 3 - Rio de Janeiro, Vitória e Nova Venécia -, Montanha mantém o padrão de manter com maior frequência as variantes médias-altas [e] e [o] em posição pretônica. O que nos chamou a atenção foi o percentual reduzido de variantes altas nessa posição no falar de Montanha (2,8\%), tendo em vista o percentual sempre mais alto nas outras cidades. Esse resultado pode estar relacionado ao método de composição do corpus, tendo em vista que a gravação de frases veículo pode levar a um maior monitoramento da fala pelos informantes. Além disso, algumas das palavras cujo contexto fonético poderiam levar ao alteamento podem não o ter feito por conta de características do próprio item lexical. A baixa frequência, na fala, de palavras como noviça, polir ou Zebu, por exemplo, pode fazer, segundo Viegas (1995, p. 108), com que esses itens fiquem mais resistentes à mudança.

Verificamos, então, as palavras que compunham o corpus e excluímos, de uma segunda análise de frequências, as palavras cujos contextos fonéticos não permitiriam o alteamento das vogais médias. Dessa forma, mantivemos apenas contextos em que a vogal tônica fosse alta, ou seja, [u] e [i], e alguns cujas consoantes pudessem influenciar no alteamento, conforme verificado em Silva (1991, p. 87-88). Excluídos estes contextos, obtivemos a frequência observada na Tabela 4.

Tabela 4. Distribuição de vogais médias-altas e altas na fala de Montanha

\begin{tabular}{cccc}
\hline $\begin{array}{c}\text { Variedade } \\
\text { linguística }\end{array}$ & $\begin{array}{c}\text { Médias-altas } \\
{[\mathrm{e}] \text { e }[0]}\end{array}$ & $\begin{array}{c}\text { Altas } \\
{[\mathrm{i}] \text { e }[\mathrm{u}]}\end{array}$ & $\begin{array}{c}\text { Médias-baixas } \\
{[\varepsilon] \text { e }[\mathrm{\jmath}]}\end{array}$ \\
\hline Montanha & $144 / 160=\mathbf{9 0} \%$ & $16 / 160=\mathbf{1 0} \%$ & $0 / 160=\mathbf{0} \%$ \\
\hline
\end{tabular}

Como podemos observar, ao retirarmos da análise alguns tipos de palavras, encontramos um total de $90 \%$ de vogais médias-altas, isto é, que seguem a regra de manutenção, tendo em vista que permanecem com a mesma altura, e encontramos $10 \%$ de vogais alteadas. Ainda que essa quantia tenha aumentado em comparação a que foi encontrada para Montanha na Tabela 4, os falantes 
de Montanha privilegiaram a manutenção das vogais médias-altas ao invés do alteamento. É importante frisar, entretanto, que algumas características de alguns itens lexicais do corpus podem ter feito com que eles ficassem mais resistentes à variação. Torna-se necessário, portanto que, posteriormente, sejam feitos novos trabalhos a fim de refutar ou ratificar o do fenômeno do alteamento de pretônicas em Montanha.

Observamos, na Tabela 4, que, com a retirada de algumas palavras, não houve nenhuma ocorrência de vogais médias-baixas em posição pretônica. Isso ocorre pois tais vogais só aconteceram em ambientes que não permitiriam o alteamento de [e] e de [o]. Considerando, no entanto, a quantia de ocorrências de vogais pretônicas médias-baixas da Tabela 4, encontramos resultados parecidos com os das outras cidades capixabas (Montanha: 17,3\%; Vitória: 18,1\%; e Nova Venécia: 18,9\%), mas bem distantes do encontrado para o Rio de Janeiro $(3,3 \%)$ e Salvador $(59,3 \%)$. Isso corrobora os estudos de Celia (2004) e Leite (2014) em relação ao fato de o Espírito Santo ser uma zona de transição entre o subfalar fluminense e o subfalar baiano.

Para prosseguir na análise dos dados, verificamos a ocorrência das três variantes estudadas, de acordo com cada vogal tônica. $\mathrm{O}$ resultado está apresentado na Tabela 5.

Podemos observar mais claramente, na Tabela 5, a presença dos contextos categóricos dos quais falamos anteriormente. Em palavras cujas tônicas tinham as vogais ou ditongos [ey], [e] e [ow], a manutenção da pretônica média-alta é uma regra categórica. $\mathrm{O}$ resultado para o efeito da tônica em [e] ratifica o trabalho de Silva $(1989 ; 1991)$, que já havia observado tal regra. Em nossos dados, no entanto, diferente do que ocorre no trabalho de Silva $(1989 ; 1991)$, além da manutenção da vogal média-alta diante da vogal tônica [o], há sete casos de abaixamento da vogal. O motivo para isso é o uso da palavra cegonha, cuja pretônica realizou-se como a média-baixa $[\varepsilon]$. Conforme verificado por Leite (2014, p. 95), para o falar de Vitória/ES, isso pode ser influência

Tabela 5. Distribuição das pretônicas de acordo com a vogal tônica

\begin{tabular}{|c|c|c|c|c|}
\hline Vogal tônica & Exemplos & Médias-Alta & Altas & Médias-Baixa \\
\hline [i] & mex[i]rica & $80 / 87=92,0 \%$ & $7 / 87=8,0 \%$ & 0 \\
\hline [u] & $v[u] d u$ & $42 / 48=87,5 \%$ & $6 / 48=12,5 \%$ & 0 \\
\hline [ey] & mot[o]queiro & $48 / 48=100 \%$ & 0 & 0 \\
\hline [e] & $\mathrm{n}[\mathrm{o}$ velo & $88 / 88=100 \%$ & 0 & 0 \\
\hline [ow] & beb[e]douro & $8 / 8=100 \%$ & 0 & 0 \\
\hline [o] & $c[\varepsilon] g o n h a$ & $57 / 64=89,1 \%$ & 0 & $7 / 64=10,9 \%$ \\
\hline$[\varepsilon]$ & $\mathrm{p}[\varepsilon]$ teca/m[u]queca & $39 / 64=60,9 \%$ & $3 / 64=4,7 \%$ & $22 / 64=34,4 \%$ \\
\hline [0] & $\mathrm{s}[\varepsilon]$ rrote & $42 / 90=46,7 \%$ & 0 & $48 / 90=53,3 \%$ \\
\hline [a] & $\mathrm{p}[\varepsilon] \mathrm{daço/[i]spada}$ & $82 / 111=73,9 \%$ & $1 / 111=\mathbf{0 , 9} \%$ & $28 / 111=25,2 \%$ \\
\hline
\end{tabular}

da consoante velar seguinte - nesse caso, /g/. De acordo com o que foi observado por linguistas como Bisol (1981), Silva (1989) e Yacovenco (1993), outro caso em que a consoante exerceu alguma influência sobre a vogal em nosso corpus foi o de moqueca, em que a consoante bilabial precedente levou à realização da vogal alta $[\mathrm{u}]$ na pretônica, embora houvesse, na sílaba tônica seguinte, uma vogal média-baixa $[\varepsilon]$.

Para encontrar os resultados dos pesos relativos (cf. SCHERRE \& NARO, 2003), retiramos, da segunda rodada no GoldVarbX, as variantes altas e os contextos de tônicas de efeito categórico ou invariante, no caso, $100 \%$. Trabalhamos, dessa forma, com as variantes médias-altas e com as médias-baixas, nos contextos da vogal tônica [a], [ع] ou [ग], que consistiram em 111, 64 e 90 ocorrências, respectivamente.

$\mathrm{Na}$ projeção dos pesos relativos, em relação à manutenção de [e] e [o], a primeira variável selecionada pelo programa como de maior relevância para nossa pesquisa foi a faixa etária (Tab. 6).

Tabela 6. Efeito da faixa etária na manutenção das variantes médias-altas [e] e [o]

\begin{tabular}{ccc}
\hline Faixa etária & Percentagens & Peso relativo \\
\hline $18-30$ anos & $111 / 131=\mathbf{8 4 , 7 \%}$ & $\mathbf{0 , 8 0 7}$ \\
$31-50$ anos & $52 / 130=\mathbf{4 0 , 0} \%$ & $\mathbf{0 , 1 9 1}$ \\
Total & $163 / 261=\mathbf{6 2 , 5 \%}$ & \\
\hline
\end{tabular}

Como podemos observar na Tabela 6 , a faixa etária de 18 a 30 anos favoreceu o uso das variantes [e] e [o]. Esse resultado, corrobora os estudos de Yacovenco (1993) e de Bisol (1981) e pode ser um forte indício de que uma mudança esteja ocorrendo na fala de Montanha, como está ocorrendo no falar carioca e no falar gaúcho. Um estudo com mais faixas etárias mostra-se interessante para comprovar essa observação.

A estrutura da palavra foi a segunda variável escolhida pelo GoldVarb X como de maior significância estatística (Tab. 7, adiante).

Conforme podemos observar na Tabela 7, palavras formadas por duas pretônicas, uma tônica e uma postônicafinal, como serenata ou dezenove, favoreceram o uso das variantes médiasaltas [e] e [o] em $91,7 \%$ dos casos com peso relativo de 0,931 . Relativamente à percentagem total de $62,5 \%$, a estrutura formada por uma pretônica, uma tônica e uma postônica-final, como em topete ou peteca, desfavoreceu ligeiramente o uso dessas variantes, tendo em vista que, nessa estrutura de palavras, foram 
Tabela 7. Efeito da estrutura da palavra na manutenção das médias-altas [e] e [o]

\begin{tabular}{|c|c|c|}
\hline Estrutura da Palavra & Percentagens & Peso relativo \\
\hline Palavras formadas por pretônica + pretônica + tônica + postônica-final (Ex.: serenata) & $44 / 48=91,7 \%$ & 0,931 \\
\hline Palavras formadas por pretônica + tônica + postônica-final (Ex.: topete) & $76 / 125=60,8 \%$ & 0,442 \\
\hline Palavras formadas por pretônica + tônica (Ex.: forró) & $43 / 88=48,9 \%$ & 0,252 \\
\hline Total & $163 / 261=62,5 \%$ & \\
\hline
\end{tabular}

registrados $60,8 \%$ de [e] e [o], com peso relativo de 0,442 , apresentando um efeito intermediário. As palavras formadas por uma pretônica e uma tônica, como sofá ou regar, foram as que mais desfavoreceram o uso de [e] e [o] $(0,252)$ e, inversamente, favorecem mais o abaixamento $(0,748)$.

A terceira variável selecionada para a manutenção de [e] e de [o] foi o tipo da vogal tônica (Tab. 8).

Tabela 8. Efeito do tipo de vogal tônica na manutenção das médias-altas [e] e [o]

\begin{tabular}{ccc}
\hline Vogal tônica & Percentagens & Peso relativo \\
\hline$[a]$ & $82 / 110=\mathbf{7 4 , 5} \%$ & $\mathbf{0 , 7 0 4}$ \\
{$[\varepsilon]$} & $39 / 61=\mathbf{6 3 , 9} \%$ & $\mathbf{0 , 5 1 8}$ \\
{$[0]$} & $42 / 90=\mathbf{4 6 , 7 \%}$ & $\mathbf{0 , 2 4 9}$ \\
Total & $163 / 261=\mathbf{6 2 , 5 \%}$ & \\
\hline
\end{tabular}

Na Tabela 8, observamos que a tônica [a] foi a que mais favoreceu a escolha pelas variantes [e] e [o]. Esse resultado já era esperado, pois, como observado na Tabela 5 , em termos percentuais, as tônicas $[\varepsilon]$ e $[\supset]$ seriam as maiores responsáveis pelos casos de harmonização entre vogal pretônica e tônica. Apesar disso, a tônica $[\varepsilon]$ favoreceu ligeiramente o uso de [e] e [o] em $63,9 \%$ dos casos, com peso relativo intermediário, e a tônica [0] desfavoreceu fortemente a manutenção de [e] e [o], tendo em vista que estas só ocorreram em $46,7 \%$ dos casos e o peso relativo foi de 0,249 .

A quarta variável selecionada como mais significativa para a manutenção de [e] e [o] foi a repetição da palavra na frase-veículo (Tab. 9). Lembramos que incluímos essa variável em nossa análise, pois queríamos saber em qual repetição das palavras analisadas os falantes monitorariam mais suas falas. Dessa forma, esta variável foi constituída pela primeira e pela quarta repetição de cada falante de Montanha.

Tabela 9. Efeito da repetição na manutenção das variantes médias-altas [e] e [o]

\begin{tabular}{|c|c|c|}
\hline Repetição & Percentagens & Peso relativo \\
\hline 4⿳亠口了 repetição & $90 / 130=69,2 \%$ & 0,662 \\
\hline 1a repetição & $73 / 131=55,7 \%$ & 0,379 \\
\hline Total & $163 / 261=62,5 \%$ & \\
\hline
\end{tabular}

Na Tabela 9, observamos que a 4⿳亠丷⿵冂⿱⺊口灬 repetição foi a que mais favoreceu a manutenção das vogais [e] e [o]. Sobre a mudança de estilo dos falantes durante a gravação, Labov (2008 [1972]) pondera que não há falante de estilo único, pois pode-se variar o modo de falar em função da atenção que se presta à fala. Nesse sentido, pode ser que, até chegar à 4a repetição, o informante tenha elevado o grau do automonitoramento de sua fala e evitado o uso do abaixamento das pretônicas [e] e [o].

A quinta e última variável selecionada como significativa na manutenção das vogais [e] e [o] foi a anterioridade/posterioridade da própria vogal pretônica (Tab. 10).

Tabela 10. Efeito da anterioridade/posterioridade da pretônica na manutenção das variantes médias-altas [e] e [o]

\begin{tabular}{lcc}
\hline \multicolumn{1}{c}{ Anterioridade/Posterioridade } & Percentagens & Peso relativo \\
\hline Vogal média pretônica posterior [o] & $82 / 124=\mathbf{6 6 , 1} \%$ & $\mathbf{0 , 6 2 9}$ \\
Vogal média pretônica anterior [e] & $81 / 137=\mathbf{5 9 , 1 \%}$ & $\mathbf{0 , 3 8 3}$ \\
Total & $163 / 261=\mathbf{6 2 , 5 \%}$ & \\
\hline
\end{tabular}

Na Tabela 10, observamos que as vogais pretônicas posteriores foram as que mais favoreceram a regra de manutenção, ou seja, os contextos em que a vogal pretônica era [o] fizeram com que esta se mantivesse em sua posição sem altear para [u] ou abaixar para [॰]. Em contrapartida, a vogal média pretônica anterior desfavoreceu a manutenção, favorecendo, consequentemente, o abaixamento.

\section{Considerações finais}

O objetivo de nosso artigo foi apresentar os resultados relativos à análise acústica e variacionista das vogais médias pretônicas faladas em Montanha, cidade que fica ao norte do Espírito Santo e faz divisa com a Bahia e com Minas Gerais. Buscamos, ainda, comparar o que foi encontrado com os resultados de outras cidades.

Assim como em outras variedades do PB, identificamos que as vogais médias pretônicas podem se comportar de três formas na fala de Montanha: a partir 
do alçamento de uma vogal média-alta para uma alta (ex.: mexerica - mexirica; moqueca - muquєca); a partir da manutenção da vogal média-alta; e a partir do abaixamento de uma média-alta para uma média-baixa (relógio - relógio; colado-colado). Dessas três formas, a mais frequente, na fala estudada, foi a manutenção da vogal média-alta. Este resultado reitera o que Yacovenco (1993) encontrou para o Rio de Janeiro, assim como o que Celia (2004) encontrou para Nova Venécia e Leite (2014) encontrou para Vitória.

Em relação à análise acústica, a partir das medidas da frequências de formantes, verificamos que as vogais [ع] e [o] de Montanha são mais baixas que as das outras cidades apresentadas, tendo em vista seu maior valor de F1. Ainda em relação a $\mathrm{F} 1$, a vogal [o] apresentou um valor baixo, sendo, dessa forma uma vogal mais alta que a de Vitória e Salvador. O mesmo ocorre com [e], que também apresenta um valor baixo para F1. Nossa hipótese inicial sobre Montanha possuir um maior valor de F1 por estar mais ao norte do Estado se comprovou, pois as vogais $[\varepsilon]$ e $[0]$ de Montanha mostraram-se mais baixas que as vogais do Rio de Janeiro, Vitória e Salvador. Além disso, o valor de F1 de Montanha se aproximou mais ao valor de F1 de Vitória. Isso pode ser um indicativo de um padrão capixaba.

Quanto à anterioridade/posterioridade, observamos, a partir dos valores de F2, que o espaço acústico da fala de Montanha é bem maior que o do Rio de Janeiro e Vitória. As vogais $[\mathrm{e}]$ e $[\varepsilon]$ se mostraram bem mais anteriores na fala de Montanha do que na das outras cidades. Em contrapartida, as vogais [o], [o] e [u] se mostraram bem mais posteriores em Montanha, dado seu valor baixo de F2.

Em relação à análise variacionista, em Montanha, o percentual de alçamento foi muito pequeno e, devido aos contextos invariantes, não foi considerado na análise de pesos relativos. Em contrapartida, o número de abaixamentos foi mais alto do que outras cidades (17,3\%) e mostrou-se coerente com os resultados de Celia (2004) para Nova Venécia $(18,9 \%)$ e com os de Leite (2014) para Vitória $(18,1 \%)$. O percentual relativamente mais alto de abaixamento no território capixaba ratifica o que Nascentes (1953) estabeleceu para essa área e coloca o estado do Espírito Santo como uma zona de transição entre o subfalar fluminense e o subfalar baiano.

Das variáveis sociais analisadas, a faixa etária apresentou maior significância estatística, ou seja, foi a primeira selecionada pelo GoldVarb X, com oposição forte entre os dois fatores. A faixa etária de 18 a 30 anos foi a que mais favoreceu a manutenção das variáveis médias-altas [e] e [o]. Nosso resultado corrobora o que foi encontrado para o Rio de Janeiro, por Yacovenco (1993), e para o Rio Grande do Sul, por Bisol (1981).
Esse comportamento pode indicar que haja uma mudança linguística em curso em direção inversa à elevação.

A segunda variável escolhida como mais significativa estatisticamente foi a estrutura da palavra. Observamos que as palavras cuja estrutura era formada por duas pretônicas + tônica + postônica-final, como serenata, favoreceram mais a manutenção das vogais médias pretônicas $[\mathrm{e}] \mathrm{e}[\mathrm{o}]$. Em contrapartida, palavras com uma pretônica + tônica, como forró e regar, desfavoreceram essa manutenção.

A terceira variável considerada mais significativa estatisticamente foi o tipo da vogal tônica. Observamos que, entre as tônicas [a], $[\varepsilon]$ e [ $]$, a que mais favoreceu a manutenção das variantes médias-altas foi a [a]. Isso ocorre pelo fato de $[\varepsilon]$ e $[\supset]$ terem levado mais à harmonização vocálica das pretônicas com as tônicas, ou seja, as pretônicas, em Montanha, tendem a assimilar a altura da tônica.

A quarta variável selecionada pelo programa foi a repetição da palavra pelos informantes na frase-veículo. Queríamos verificar, entre duas repetições das palavras

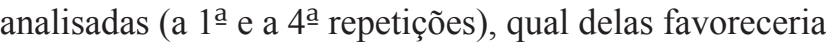
mais a manutenção da vogal média-alta e descobrimos que isso ocorria mais na quarta repetição. Tal fato pode indicar que, ao longo da gravação, os informantes passaram a se monitorar mais.

A quinta variável selecionada como significativa foi a anterioridade/ posterioridade da própria vogal pretônica. A partir dos valores de pesos relativos, observamos que as vogais posteriores foram as que mais favoreceram a manutenção das vogais médias-altas [e] e [o].

Com este trabalho sobre as vogais médias pretônicas em Montanha e com o de Celia (2004), para Nova Venécia, e o de Leite (2014), para Vitória, concluímos que os resultados apontam para o fato de o Espírito Santo se configurar como uma zona de transição entre os falares do Sul e do Norte. Além disso, na análise acústica, as vogais médias-baixas de Montanha apresentaram valores similares aos de Vitória, o que pode ser um indicativo de um possível padrão de frequências de formantes no território capixaba.

\section{Referências}

ABAURRE-GNERRE, Maria Bernadete Marques. Processos fonológicos segmentais como índices de padrões prosódicos diversos nos estilos formal e casual do português do Brasil. $\mathrm{Ca}$ dernos de Estudos Linguísticos, Campinas, v. 2, p. 23-44, 1981.

BISOL, Leda. Harmonização vocálica: uma regra variável. 1981. 281 f. Tese (Doutorado em Linguística) - Faculdade de Letras, Universidade Federal do Rio de Janeiro, Rio de Janeiro, 1981.

BOERSMA, Paul; WEENINCK, David. Praat: doing phonetics by computer. 2012. Disponível em: <www.praat.org>. 
CELIA, Gianni Fontis. As vogais médias pretônicas na fala culta de Nova Venécia. 2004. 114 f. Dissertação (Mestrado em Linguística) - Instituto de Estudos da Linguagem, Universidade Estadual de Campinas, Campinas, 2004.

CRYSTAL, David. Dicionário de linguística e fonética. Rio de Janeiro: Jorge Zahar Editora, 1988.

CRISTÓFARO-SILVA, Thaïs. Fonética e fonologia do português. 9. ed. São Paulo: Contexto, 2007.

CRISTÓFARO-SILVA, Thaïs; YEHIA, Hani Camille. Sonoridade em Artes, Saúde e Tecnologia. Belo Horizonte: Faculdade de Letras, 2009. Disponível em: <http://fonologia. org. ISBN 978-85-7758-135-1>. Acesso em: 03 set. 2016.

FANT, Gunnar. (1960). Acoustic theory of speech production. Paris: Walter de Gruyter, 1970.

KENT, Raymond; READ, Charles. Análise Acústica da Fala. São Paulo: Cortez, 2015.

LABOV, William. (1972). Padrões Sociolinguísticos. São Paulo: Parábola, 2008.

LADEFOGED, Peter. Vowels and consonants: an introduction to the sounds of languages. USA: Blackwell Publishers, 2001.

LADEFOGED, Peter; JOHNSON, Keith. A course in phonetics. 6. ed. Canadá: Wadsworth Cenage Learning, 2011.

LEITE, Melina de Figueiredo. As vogais médias pretônicas na fala de Vitória. 2014. 134 f. Dissertação (Mestrado em Estudos Linguísticos) - Programa de Pós-Graduação em Linguística, Universidade Federal do Espírito Santo, Vitória, 2014.

MIRANDA, Irma Iunes. Análise acústico-comparativa de vogais do (PB) com vogais do inglês norte-americano. 2012. 147 f. Dissertação (Mestrado em Estudos Linguísticos) Programa de Pós-Graduação em Linguística, Universidade Federal do Espírito Santo, Vitória, 2012.

MIRANDA, Irma Iunes; MEIRELES, Alexsandro Rodrigues. Descrição acústica das vogais tônicas da fala capixaba. Letras de Hoje [online] , v. 47, p. 325-332, 2012.
MORAES, João; CALLOU, Dinah; LEITE,Yonne. O sistema vocálico do português do Brasil: caracterização acústica. In: KATO, Mary Aizawa. (Org.). Gramática do português falado. Vol.V: Convergências. 2. ed. São Paulo: FAPESP; Editora da UNICAMP, 2002. p. 33-52.

NASCENTES, Antenor. O linguajar carioca. Rio de Janeiro: Organização Simões, 1953.

SANKOFF, David; TAGLIAMONTE, Sali. A.; SMITH, Eric. Goldvarb $X-$ A multivariate analysis application. Toronto: Departament of Linguistics; Ottawa: Department of Mathematics. 2005. Disponível em: $<$ http://individual.utoronto. ca/tagliamonte/goldvarb.html>. Acesso em: 02 jan. 2016.

SCHERRE, Maria Marta Pereira; NARO, Anthony Julius. Análise quantitativa e tópicos de interpretação do Varbrul. In: MOLLICA, Maria Cecília; BRAGA, Maria Luiza (Org.). Introdução à sociolingüística - o tratamento da variação. São Paulo: Contexto, 2003. p. 147-177.

SILVA, Myrian Barbosa da. As pretônicas no falar baiano: a variedade culta de Salvador. 1989. Tese (Doutorado em Língua Portuguesa) - Faculdade de Letras, Universidade Federal do Rio de Janeiro, Rio de Janeiro, 1989.

SILVA, Myrian Barbosa da. Um traço regional na fala culta de Salvador. Organon, v. 5, n. 18, p. 79-89, 1991.

VIEGAS, Maria do Carmo. O alçamento de vogais médias e os itens lexicais. Revista de Estudos Linguísticos, Belo Horizonte, v. 4, n. 2, p. 101-123, jul.-dez. 1995.

YACOVENCO, Lilian. As vogais médias pretônicas no falar culto carioca. 1993. 185 f. Dissertação (Mestrado em Língua Portuguesa) - Faculdade de Letras, Universidade Federal do Rio de Janeiro, Rio de Janeiro, 1993.

Recebido: 27 de setembro de 2016

Aprovado: 08 de março de 2017

Contatos: meirelesalex@gmail.com vivi_paula16@yahoo.com.br mscherre@gmail.com 